\title{
The Development of Social Play in Bottlenose Dolphins (Tursiops truncatus)
}

\author{
Angela D. Mackey, ${ }^{1 *}$ Radhika N. Makecha,${ }^{2}$ and Stan A. Kuczaj, II $^{1}$ \\ ${ }^{1}$ University of Southern Mississippi \\ ${ }^{2}$ Eastern Kentucky University \\ *Corresponding author (Email: angmack@gmail.com)
}

Citation - Mackey, A. D., Makecha, R. N., \& Kuczaj, S. A., II. (2014). The development of social play in bottlenose dolphins (Tursiops truncatus). Animal Behavior and Cognition, 1(1), 19-35. doi:10.12966/abc.02.02.2014

\begin{abstract}
For the young of many species, social play is an important aspect of development. Previous research has shown that bottlenose dolphin calves engage in social play early in life. Despite these observations, little is known about the development of social play in this species. The present study examined the social play behavior of three aquarium-housed bottlenose dolphin calves during their first year of life. We were particularly interested in the partner with whom each calf played as well as the initiator of social play bouts. Each calf was observed from birth until the end of its first year and all bouts of social and solitary play were recorded during observation sessions. While the calves engaged in both social and solitary play throughout their first year, play became increasingly social as they aged. The calves also became more likely to initiate social play interactions with increasing age. A calf's first social play partner was typically its mother, but other calves quickly replaced the mother as the most common play partner. When it came to play partner preferences, we found that calves of similar age were preferred as play partners, but age similarity became less characteristic of play partners as the calves grew older. These findings likely reflect changes in the developmental competence of each of the calves individually, and support the notion that calves use social play to challenge themselves.
\end{abstract}

Keywords - Social play, Bottlenose dolphins; Development; Play partner preference; Tursiops truncatus

Social play, or play behavior directed at conspecifics (Burghardt, 2005), is evident in a variety of species and is especially salient in those with complex social structures. Social play has been reported in both human (e.g., Doyle, Connolly, \& Rivest, 1980; Eckerman, Whatley, \& Kutz, 1975; Fry, 2005) and non-human primates (e.g., Cordoni \& Palagi, 2011; Harlow \& Harlow, 1962; Hoff, Nadler, \& Maple, 1981; de Oliveira, Ruiz-Miranda, Kleiman, \& Beck, 2003), as well as a variety of terrestrial mammals (e.g., Byers, 1977; Drea, Hawk, \& Glickman, 1996; Henry \& Herrero, 1974; Lee, 1987; Wemmer \& Fleming, 1974), aquatic mammals (e.g., Blomqvist, Mello, \& Amundin, 2005; Essapian, 1953; Gentry, 1974; Kuczaj, Makecha, Trone, Paulos, \& Ramos, 2006; Mann \& Smuts, 1999; McBride \& Hebb, 1948; Renouf \& Lawson, 1986; Spinelli, Nascimento, \& Yamamato, 2002; Sylvestre, 1985), birds (e.g., Diamond \& Bond, 2003; Pozis-Francios, Zahavi, \& Zahavi, 2004), and even reptiles (e.g., Burghardt, 1998). The ubiquitous presence of social play in highly social species highlights the need for studies aimed at understanding the various aspects of this behavior and the role it plays in social interactions.

One aquatic species in which social play is evident, but little studied, is the bottlenose dolphin, Tursiops truncatus (Essapian, 1953; Kuczaj et al., 2006; Mann \& Smuts, 1999; McBride \& Hebb, 1948; Paulos, Trone, \& Kuczaj, 2010). Social play has been reported as early as the first week of life in both free-ranging and aquarium-housed dolphins (Brown \& Norris, 1956; DeLong, 1999; Essapian, 1953; 
Kuczaj et al., 2006; Mann \& Smuts, 1999; Tayler \& Saayman, 1972) and involves a variety of behaviors. These behaviors include homosexual play, reciprocal chasing (each individual takes turns chasing each other, often involving the use of an object such as seaweed or a ball), and mimicking both familiar and novel play behaviors (Brown \& Norris, 1956; Essapian, 1953; Kuczaj et al., 2006; McBride \& Hebb, 1948; Mann \& Smuts, 1999; Pace, 2000; Tayler \& Saayman, 1972).

Although dolphins of all ages are known to participate in play, young bottlenose dolphins (i.e., infants and juveniles) frequently engage in play (Greene, Melillo-Sweeting, \& Dudzinski, 2011; Kuczaj et al., 2006; Mann \& Smuts, 1999; McBride \& Hebb, 1948; Tayler \& Saayman, 1972), a fact which indicates that play may be an important component of development. Social play in particular may aid young animals in learning to interact appropriately with various members of their group. This can include forging long-lasting relationships with group members, establishing a position within the group's social hierarchy, and assessing their own capabilities relative to conspecifics (Bekoff \& Byers, 1981; Fagen, 1981; Martin \& Caro, 1985; Palagi, Cordoni, \& Borgognini Tarli, 2004; Poirier \& Smith, 1974; Thompson, 1998).

Participation in social play may also serve to prepare an animal for adult activities, facilitating the development of the skills necessary for survival (e.g., hunting, predator avoidance, mate acquisition; Bekoff \& Byers, 1981; Fagen, 1981; Guinet, 1991; Loizos, 1967). This idea is supported by the observation that social play behaviors occurring during a young animal's development often resemble more mature activities later seen during adulthood, although during play the behaviors are typically exaggerated and occur in variable sequences (Bekoff \& Byers, 1981; Coelho \& Bramblett, 1982; Harcourt, 1991; Martin \& Caro, 1985). For example, rough, socio-sexual play often observed in male bottlenose dolphin calves is thought to aid in the development of skills necessary for the formation and maintenance of adult male alliances, while certain social play behaviors of both male and female bottlenose dolphins are similar to adult courtship behaviors (Gibson \& Mann, 2008a; Mann, 2006).

Social play may also play a role in the development of culture within a species, whereby an individual acquires behavior(s) through the process of social learning (Avital \& Jablonka, 2000; Boyd \& Richerson, 1988; Kuczaj et al., 2006; Rendell \& Whitehead, 2001). While cultural transmission can occur between any members of a group (e.g., mother to infant, adult to adult), young animals may play a significant role in the process, particularly through interactions with peers. Kuczaj et al. (2006) reported that bottlenose dolphin calves were the most likely age class to produce novel play behaviors and also the most likely to imitate novel play behaviors, especially those produced by other calves. The incorporation of novel behaviors into a group's behavioral repertoire through successive generations allows for behavioral flexibility, aiding in an individual's adaptation to novel environments and situations, and ultimately contributing to the survival of a species. (Gottlieb, 2002; Kuczaj et al., 2006; Laland, OdlingSmee, \& Feldman, 2000; Rendell \& Whitehead, 2001).

Who an animal plays with is also a key component in an individual's development. Harlow and Harlow's (1962) series of experiments on maternal and infant relations in rhesus macaques (Macaca mulatta) indicated that peer-peer interactions, particularly play interactions, were an important aspect of normal social development. Mother-infant interactions alone were not sufficient to facilitate the development of species-typical behaviors (e.g., play, sexual, and defensive behaviors) but mother-infant interactions coupled with infant-infant social play interactions during the first few months of life resulted in species-typical development.

Peers, then, may play an important role in the development of species-typical social behaviors. Peers are frequently a young animal's most common play partners (e.g., Altmann, 1962; Kuczaj et al., 2006; Thompson, 1996b). Observations on vervet monkey (Cercopithecus aethiops sabaeus) infants revealed that individuals played more often with infants that were closer to their own age than those that were older (Govindarajulu, Hunte, Vermeer, \& Horrocks, 1993). Specifically, play bouts with similaraged animals were longer lasting, and the duration of play bouts decreased with an increase in age difference between partners. Such preference for play amongst like-aged partners has been demonstrated in other primates, including chimpanzees (Pan troglodytes; Cordoni \& Palagi, 2011; Goodall, 1968), western lowland gorillas (Gorilla gorilla gorilla; Maestripieri \& Ross, 2004), Japanese macaques 
(Macaca fuscata; Itani, 1954), crab-eating macaques (Macaca fascicularis; Fady, 1969), baboons (Papio anubis; Cheney, 1978; Owens, 1975), Japanese monkeys (Macaca fuscatai; Imakawa, 1990), and rhesus monkeys (Macaca mulatta; Tartabini, 1991), as well as non-primate mammals (e.g., Cuvier's gazelle, Gazella cuvieri, Gomendio, 1988; Belding's ground squirrel, Spermophilis beldingi, Holmes, 1994; bison, Bison bison, Rothstein \& Griswold, 1991; sable antelope, Hippotragus niger, Thompson, 1996b).

In bottlenose dolphins, both mothers and peers play important roles in calf social play interactions. While the nature of mother-calf interactions varies as a function of an individual mother's maternal style (Hill, Greer, Solangi, \& Kuczaj, 2007), the typical pattern is one in which mothers and newborn calves remain in close proximity during their first few months of life (Chirighin, 1987; Cockcroft \& Ross, 1990; Eastcott, \& Dickinson, 1987; Gubbins, McCowan, Lynn, Hooper, \& Reiss, 1999; Gibson \& Mann, 2008a, 2008b; Hill et al., 2007; Mann \& Smuts, 1999; McBride \& Kritzler, 1951; Reid, Mann, Weiner, \& Hecker, 1995; Tavolga \& Essapian, 1957). As calves mature, their independence and exploration of the environment increases, as does their tendency to engage in social play with other similarly-aged animals within the group (Chirighin, 1987; DeLong, 1999; Gibson \& Mann, 2008a).

Over the past 40 years, numerous studies of free-ranging and aquarium-housed dolphins have allowed researchers to investigate the nature of social relationships among dolphin group members, revealing much about delphinid social behavior. Such studies range from broad "big picture" topics such as social structure (e.g., Lusseau et al., 2003; Rogers, Brunnick, Herzing, \& Baldwin, 2004; Wells, Scott, \& Irvine, 1987) to specific social interactions, such as mother-calf interactions (e.g., Gibson \& Mann, 2008a, b), the "herding" behavior of male alliances (Connor, Smolker \& Bejder, 2006; Connor, Smolker, \& Richards, 1992), and social tactile behaviors (e.g., Dudzinski, Gregg, Ribic, \& Kuczaj, 2012; Dudzinski et al., 2009; Tamaki, Morisaka, \& Taki, 2006). Although a few studies have reported on social play in bottlenose dolphins (Kuczaj, Paulos, \& Ramos, 2005; Mann \& Smuts, 1999; McBride \& Krtizler,1951; Tayler \& Saayman, 1972), no study to date has investigated the developmental patterns of social play in this species, including the role of different play partners in these interactions. Therefore, the aim of the present study was to examine the developmental changes in the play behavior of a group of captive bottlenose dolphin calves during their first year life, with specific emphasis on social play. Play partner preferences were examined, as was the stability of these preferences over time. Additionally, the initiator of each play bout was examined in order to assess the effects of development on social play initiation patterns.

\section{Method}

\section{Subjects and facility}

The animals in the current study were three bottlenose dolphin (Tursiops truncatus) calves born and housed in a 90' diameter, 20' deep pool at Marine Life Oceanarium in Gulfport, Mississippi. The date of birth and sex of each calf are presented in Table 1. Apart from the births of these calves, the group composition remained consistent throughout the study, with four adult females and one adult male. An older fourth calf, JA, was also present during the study, but was only treated as a focal animal for the analysis of play partner preferences.

Table 1

Dolphin Calf Characteristics

\begin{tabular}{lll}
\hline Dolphin & Sex & Date of birth \\
\hline JA & male & $6 / 18 / 97$ \\
KA & female & $9 / 28 / 98$ \\
NO & male & $3 / 5 / 99$ \\
JO & male & $3 / 19 / 99$ \\
\hline
\end{tabular}




\section{Design and procedure}

Observations were conducted on the entire group of dolphins as part of a long-term study of the behavior of captive bottlenose dolphins. On average, six observations per week were conducted over a three-year period (1998-2000). All observations were conducted during daylight hours, and data were collected mainly at the surface of the pool, although some portions of observations took place through several underwater viewing areas. During observations all-occurrence and ad libitum methods (Altmann, 1974) were used to record detailed information on the play of individual animals. Data were not collected during a show or during the fifteen minutes before or after a show in order to minimize the effects of the show on the dolphins' behavior. Observations were included in the analysis only if they were a minimum of 30 minutes duration. A summary of the number of hours each calf was observed in each month of its first year of life is provided in Table 2. Although the number of hours a calf was observed each birth month was not similar across calves, the total number of hours of observation for each calf in its first year was consistent $[F(2,33)=0.019, p=0.981]$.

Table 2

\begin{tabular}{llll}
\multicolumn{3}{c}{ Monthly Hours of Observation for Each Calf During its First Year of Life } \\
\cline { 2 - 4 } Month of life & KA & Hours of observation \\
\cline { 2 - 4 } 1 & 6.0 & 29.7 & JO \\
2 & 11.1 & 23.6 & 29.8 \\
3 & 7.0 & 4.0 & 11.7 \\
4 & 18.7 & 47.4 & 21.6 \\
5 & 21.2 & 57.2 & 50.5 \\
6 & 26.0 & 19.2 & 51.4 \\
7 & 26.2 & 19.9 & 11.2 \\
8 & 5.0 & 16.4 & 17.0 \\
9 & 35.8 & 16.1 & 17.9 \\
10 & 60.1 & 15.0 & 23.5 \\
11 & 30.5 & 7.7 & 3.6 \\
12 & 17.8 & 7.7 & 11.8 \\
Total & $\mathbf{2 6 5 . 4}$ & $\mathbf{2 6 3 . 9}$ & 1.5 \\
\hline
\end{tabular}

During observations, all instances of play were recorded and divided into two categories: social and solitary play (see Appendix for an ethogram of target play behaviors). Social play bouts were defined as a series of play behaviors that involved two or more dolphins. Social play bouts were considered to end when one of the calves involved 1) engaged in a non-play activity, 2) began to engage in solitary play, or 3 ) the series of play behaviors ceased for more than $10 \mathrm{~s}$. Solitary play bouts involved a series of play behaviors performed by a single animal and were considered to end when 1) the individual engaged in a non-play activity, 2) a social play bout was initiated by the calf or another animal, or 3) the series of solitary play behaviors ended for more than $10 \mathrm{~s}$.

\section{Data analyses}

Developmental pattern of social play. Our first analysis investigated the development of social play behavior during the first year of life. A monthly percentage of social play was calculated for each calf by dividing the number of social play bouts observed in each birth month by the total number of play bouts (social and solitary combined) observed that month and multiplying by 100 . This percentage was then plotted and a line of best fit was generated in order to examine the pattern of social play for each 
calf. We also examined month-by-month changes in the type of play partner involved in a calf's social play interactions by dividing the number of social play bouts involving a particular category of partner (mother, other adult, other calf) by the total number of social play bouts observed for that calf (multiplied by 100 to obtain a percentage). As before, these percentages were plotted for each calf.

Initiation of social play. To investigate the initiation patterns of social play, all social play bouts in which an initiator could be established were tabulated. In many cases, the initiator was not recorded or could not be determined as the play interaction was already in progress when it was observed. As a result, the original social play data set was reduced by approximately $60 \%$. A monthly percentage of initiations was calculated for each calf by dividing the number of social play bouts initiated by that calf by the total number of social play bouts observed, multiplied by 100 .

In order to ensure that social play interactions were not pseudo-replicated, each social play bout was randomly assigned to one of the calves involved in the interaction. For example, for social play bouts involving all three calves, approximately $33 \%$ were assigned to KA, $33 \%$ to NO, and $33 \%$ to JO.

Play partner preferences. As social play involving other calves was very common throughout the study, our third analysis examined whether the calves showed a preference for a particular play partner. The data for this analysis were limited to 1) interactions in which only two calves were involved to reduce any bias resulting from the presence of additional play partners, and 2) the twelve months in which all of the calves were available for play (i.e., twelve months from the birth of JO). A fourth calf (JA) was available as a play partner and was also included in this analysis. As before, play bouts involving JA and another calf were randomly assigned to only one of the participants in order to avoid pseudo-replication.

For each of the four calves all social play bouts were tabulated for every possible dyad and chisquare goodness of fit tests were used to analyze play partner preferences. In order to further investigate whether play partner preferences changed over time, each social play bout was classified by age similarity. "Similar-older" was used to code social play interactions that occurred between the two oldest calves (JA and KA), "similar-younger" was used to code social play interactions between the two youngest calves (NO and JO), and "mixed age" was used for any social play interactions that occurred between one of the oldest calves and one of the youngest calves. A monthly percentage of each age classification was calculated for each calf, which was then averaged across calves and plotted.

\section{Results}

\section{Developmental patterns of social play}

As illustrated in Figure 1 (A and B), NO and JO showed a similar quadratic-shaped pattern of social play behavior, with social play being high during the first few months, decreasing and remaining low for several months, and then once again increasing toward the end of the first year. Alternatively, KA's social play pattern was cubic-shaped rather than quadratic. Initially, KA followed a pattern similar to that of $\mathrm{NO}$ and $\mathrm{JO}$, with the percentage of social play starting high and decreasing within the first few months. However, KA's social play began to increase again after month six, rather than toward the end of her first year as it did for the other two calves. Interestingly, the timing of this increase in social play corresponds with the birth of NO and JO.

It is important to note at this point that the observed decrease in social play among the calves is not a reflection of a general decrease in play behavior. The calves maintained a high rate of play throughout the study. Rather, as the percentage of social play is the inverse of solitary play, this decrease represents a switch from the calves engaging in social play to engaging in solitary play. 
A)

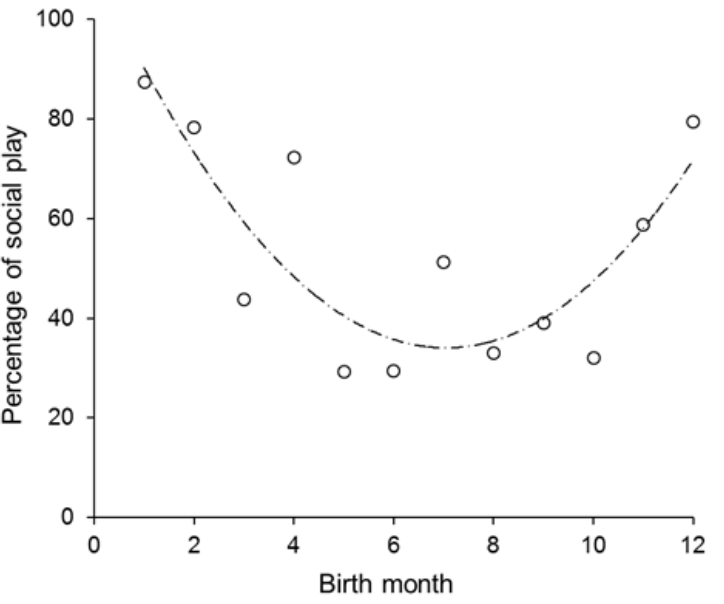

C)

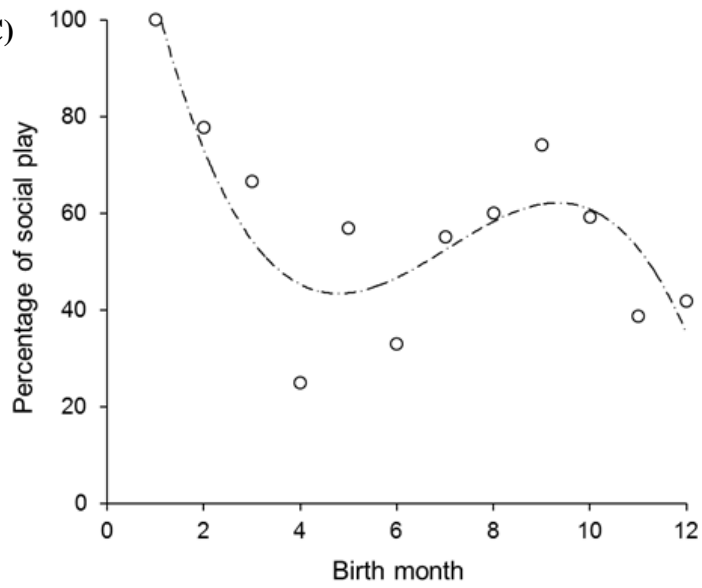

B)

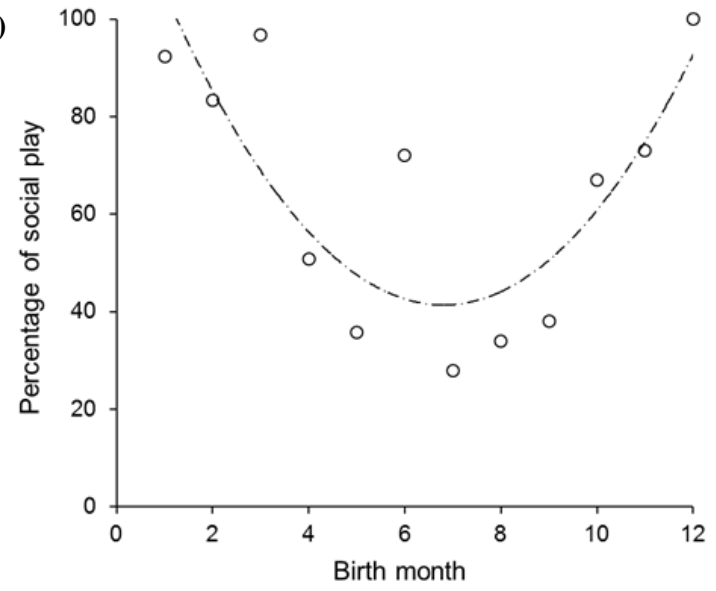

Figure 1. Percentage of social play for each calf during its first year of life. A) NO; B) JO; C) KA. (Note. Percentage of solitary play is the inverse of social play; thus, as the percentage of social play increases, the percentage of solitary play decreases).

Upon analyzing the partners involved in social play during the first year of life, we found that play with adults other than the calf's mother was very low (on average, $2.6 \%$ ). Thus, we limited our analysis to social play involving the calf's mother and other calves. For all three calves, the percentage of social play involving the calf's mother was highest in the first few months of life and decreased as the calf aged. Meanwhile, the percentage of social play involving other calves increased with age (Figure 2). While this pattern was similar among all three calves, there were individual differences in regard to the time at which peers became the most common social play partner. KA switched from playing primarily with her mother to playing with other calves in her fourth month of life, while NO began playing with calves more often than his mother in his second month. For JO, the youngest calf, other calves were more common social play partners than his mother from the beginning of his life. 
A)

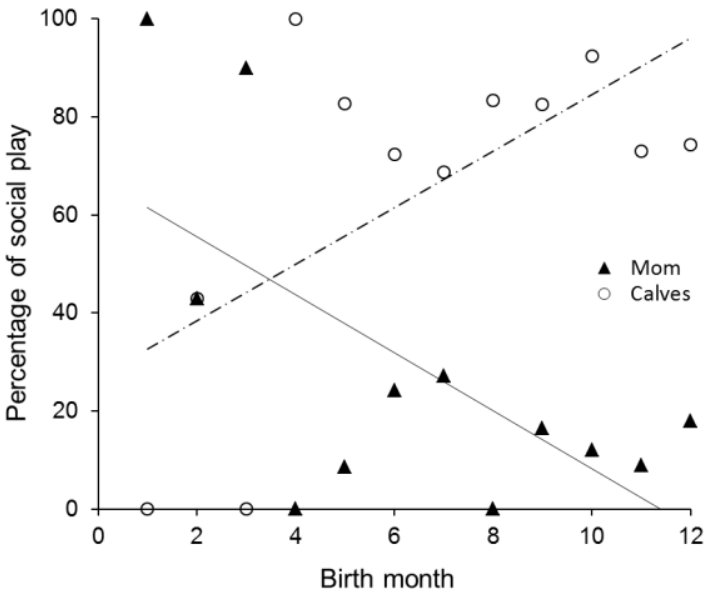

C)

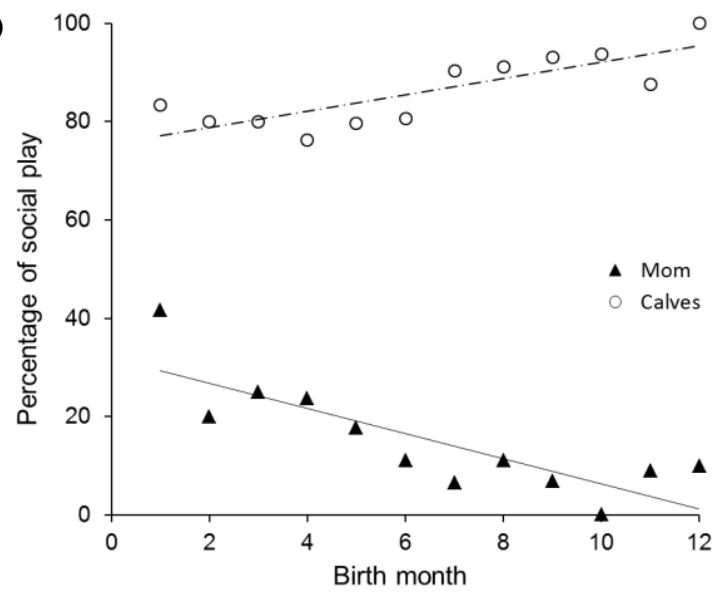

B)

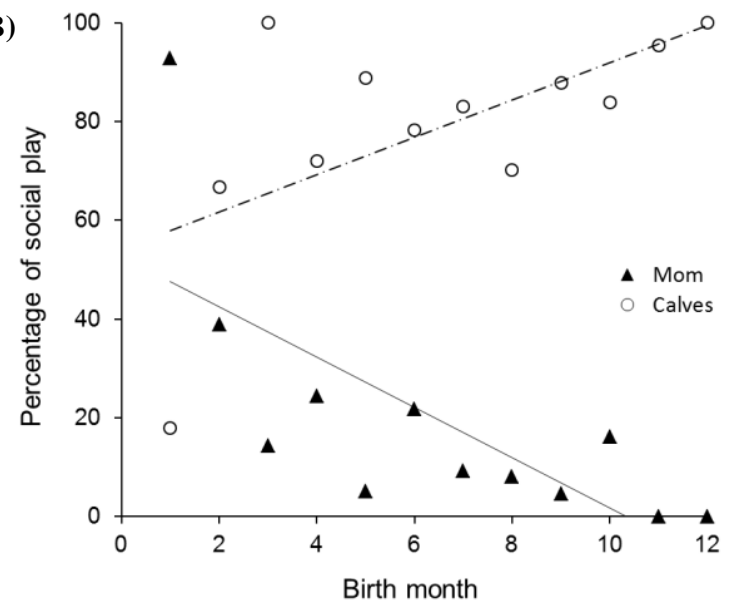

Figure 2. Percentage of social play involving a calf's mother and other calves over the first year of life. A) KA; B) NO; C) JO.

\section{Initiation of social play}

Concerning the initiation of play, we found that as calves aged they initiated social play bouts more frequently (Figure 3). As an example, NO was often involved in social play (particularly chasing) with the two older calves, JA and KA, in his first two months of life, but he initiated few of these interactions (on average 18\%). By his fifth month, NO was initiating social play more regularly (33\%), both with the older calves and with JO, who was nearly the same age. By the end of his first year, NO was initiating more than $50 \%$ of the social play bouts in which he was involved. 


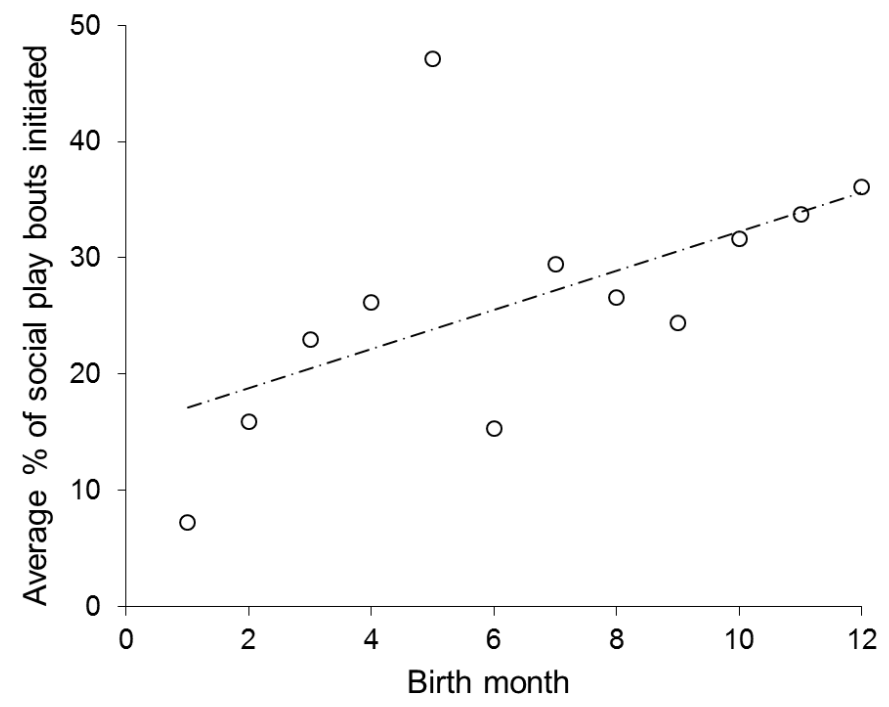

Figure 3. Percentage of social play bouts initiated during the first year of life, averaged across the three calves.

\section{Play partner preferences}

Social play that occurred during the last month of the study period always involved more than two calves. As we only analyzed social play behaviors that occurred between $t w o$ calves, this month was therefore not included in the analysis. All of the calves engaged in social play with every other calf (Table 3); however, Chi-square goodness of fit tests revealed that each calf spent a significantly greater amount of time playing with a particular individual. JA and KA were significantly more likely to play with each other $\left(\chi^{2}(2,262)=32.06, p<0.001\right.$ and $\chi^{2}(2,242)=49.56, p<0.001$, respectively), while the two youngest calves, $\mathrm{NO}$ and $\mathrm{JO}$, were more likely to engage in social play with one another $\left(\chi^{2}(2,186)=\right.$ $17.42, p<0.001)$ and $\chi^{2}(2,179)=14.42, p<0.001$, respectively).

Table 3

Total Percentage of Social Play Bouts with Each Play Partner

\begin{tabular}{|c|c|c|c|c|c|}
\hline \multirow[b]{2}{*}{ Calf } & \multicolumn{4}{|c|}{ Play partner } & \multirow[b]{2}{*}{$\mathrm{N}$ social play bouts } \\
\hline & JA & KA & NO & $\mathrm{JO}$ & \\
\hline JA & - & $59.9 \%$ & $21.4 \%$ & $18.7 \%$ & 262 \\
\hline KA & $66.5 \%$ & - & $17.8 \%$ & $15.7 \%$ & 242 \\
\hline NO & $24.2 \%$ & $23.1 \%$ & - & $52.7 \%$ & 186 \\
\hline $\mathrm{JO}$ & $27.4 \%$ & $21.8 \%$ & $\mathbf{5 0 . 8 \%}$ & - & 179 \\
\hline
\end{tabular}

Note. The most common play partner for each calf is in boldface text.

When considering the effect of age similarity on play partner preference, we found that age similarity became less of a factor in the composition of social play dyads as the calves aged. Specifically, 
we observed that the percentage of social play bouts occurring between similarly-aged calves decreased over time, while social play bouts between "mixed" ages increased (Figure 4).

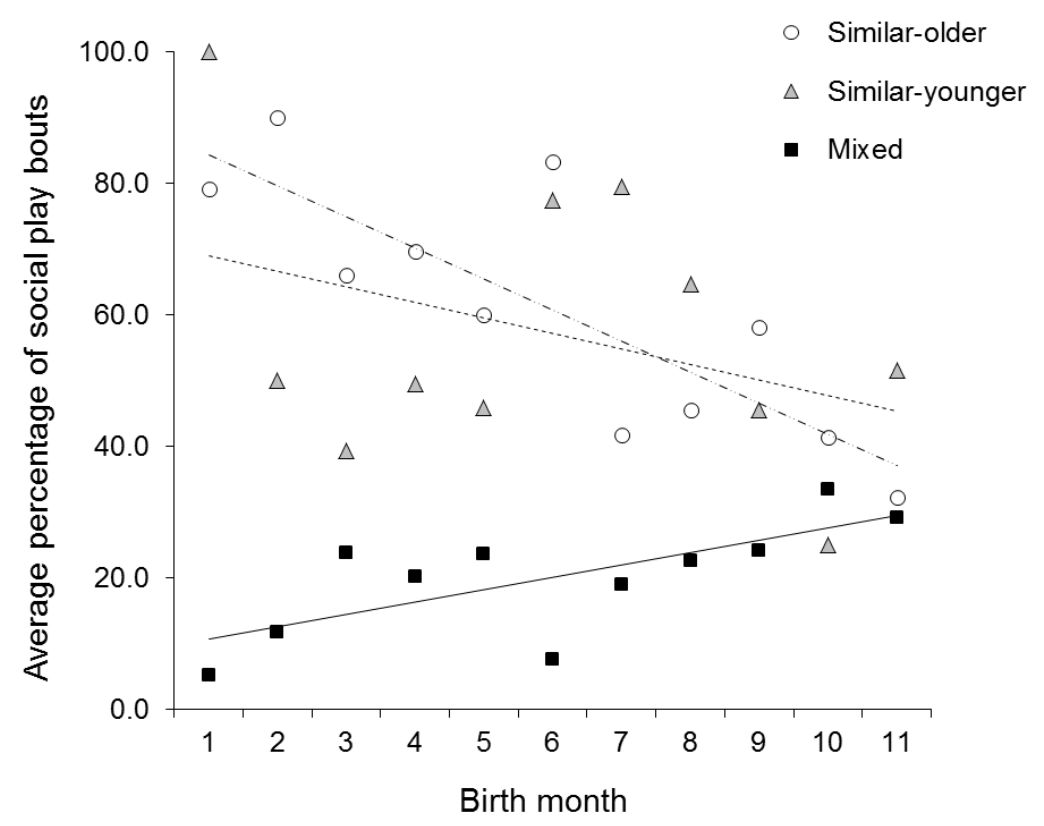

Figure 4. Changes in play partner age similarity over time. "Similar-older" denotes social play between the two oldest calves, JA and KA; "Similar-younger" denotes social play between the two youngest calves, NO and JO; and "Mixed age" denotes social play between one of the oldest calves and one of the youngest calves.

\section{Discussion}

The regular participation in social play observed in each of the calves over the first year is consistent with the notion that play may be developmentally important for bottlenose dolphin calves (Kuczaj et al., 2006, Kuczaj \& Makecha, 2008). During this time, calves are learning to interact with their environment as well as with other members of their social group. Play may also facilitate the development of motor skills in young animals, such as those used in hunting or predator avoidance (Bekoff \& Byers, 1981; Essapian, 1953; Fagen, 1981; Guinet, 1991; Loizos, 1967).

When focusing on social play behavior specifically, a similar pattern of development was observed for NO and JO. The percentage of social play was initially high during the first few months of life, but decreased as these calves began to engage more regularly in solitary play. It is possible that participation in solitary play at this time may facilitate the development of physical skills that are later incorporated into social play interactions (Thompson, 1998). For example, jumping in the air onto a ball or pinning a ball to the bottom of the pool with a body part may help a calf develop the motor skills that are useful in rough-and-tumble social play.

Additionally, this period of solitary play may be similar to the sensorimotor period in human infants (Piaget, 1952), during which time an infant is learning about the external consequences of their bodily actions. For the period of time in which the calves spent more time engaged in solitary play, they were interacting with objects (most often a ball) and learning how to manipulate them. It is possible that the outcome of interactions with these objects became increasingly predictable over time, leading the calves to switch to social play with other calves, which are much less predictable in their reactions. This switch was reflected in the increase in social play toward the end of the first year. A similar trend has been observed in humans, in which children showed a preference for play with peers as the objects available for play became more familiar (Scholtz \& Ellis, 1975). 
Although NO and JO increased their percentage of social play toward the end of the first year, they were still engaging in solitary play behaviors. During this time, the calves were likely making these solitary play behaviors more difficult, allowing them to maintain some unpredictability in the environment. Kuczaj et al. (2006) reported that object play in dolphin calves becomes increasingly complex as the calves age. It was observed that once a dolphin calf had mastered a particular behavior, the calf would introduce new variations of the behavior (e.g., tossing a ball and then tossing a ball while swimming upside down) or apply the behavior to a novel object (e.g., a buoy).

While KA's pattern of social play over the first five months of her life was similar to that of NO and $\mathrm{JO}$, she showed an increase in social play behavior between months six and nine that is lacking for the other two calves. This increase in social play behavior corresponds to the time when NO and JO were born into the social group. KA's social play at this time was mainly with JA rather than NO and JO; therefore, the increase in her social play at this time may be a reflection of an increase in overall group arousal due to the presence of the new calves.

In examining the types of partners (e.g., mother, other adult, other calf) involved in social play in the first year of life, we found that, generally, social play interactions during the first few months occurred most often between a calf and its mother. This pattern is not surprising, as many studies have reported that newborn calves remain in close proximity to their mother in the first few months of life (Chirighin, 1987; Cockcroft \& Ross, 1990; Gibson \& Mann, 2008a, b; Gubbins et al., 1999; Hill et al., 2007; Mann \& Smuts, 1999; McBride \& Hebb, 1948; McBride \& Kritzler, 1951; Mello, Nordensten, \& Amundin, 2005; Tavolga \& Essapian, 1957). However, we found that as the calves aged the percentage of social play involving their mothers decreased, while social play interactions with other calves increased. This change in type of play partner has also been observed in free-ranging bottlenose dolphin calves (Gibson \& Mann, 2008a) and is likely influenced by the fact that bottlenose dolphin calves tend to spend less time interacting with their mothers as they age (Gubbins et al., 1999; Cockcroft \& Ross, 1990; Eastcott \& Dickinson, 1987; Mann, 1997; Mann \& Smuts, 1999; Reid et al., 1995).

An increase in time spent playing with like-aged peers has been observed in other social species, including human (Eckerman et al., 1975) and non-human primates (Hoff et al., 1981). Several reasons may account for such a pattern. First, peers are often more willing to participate in a young individual's play than are adults (Eckerman et al., 1975) and may be more willing to participate in a wider variety of play behaviors (Mendl, 1988). Additionally, the play behavior of peers may be more easily duplicated, and may have an air of novelty that is greater than that of an adult (Eckerman et al., 1975; Kuczaj et al., 2006). For example, Kuczaj et al. (2006) reported that dolphin calves were more likely than adults to produce novel behaviors and young calves were also more likely to imitate other calves than they were to imitate adults. Therefore, novelty may be an important component of delphinid play, promoting the development of flexible cognitive skills that allow a young animal to adapt to novel and changing environments (Kuczaj \& Trone, 2001; Kuczaj et al., 2006; Pace, 2000; Spinka, Newberry, \& Bekoff, 2001).

While all three calves followed the same pattern in regard to social play partners, there were notable differences in the time at which other calves replaced the mother as the most common social play partner. KA consistently played with other calves more often than with her mother starting in her fourth month, whereas JO's social play behaviors mainly involved other calves from his first month of life. The presence of other calves may account for this. Our results indicate that there is a relationship between the number of calves available as play partners and the frequency of peer-peer play interactions. As the number of similarly-aged play partners available for social play increased, the shift from mother to peers as play partners occurred at an earlier stage in development. For example, KA, who only had one older calf available for social play, exhibited a higher percentage of play with other calves than with her mother at a later time than $\mathrm{JO}$, who had three older calves with which to play upon his birth. Unfortunately, it is impossible to determine whether this difference was simply the result of an increase in the number of opportunities for social play interactions or if there is another contributing factor (e.g., a difference in the initiation patterns among the calves). 
Differences in maternal style among the mothers of the three calves may explain the observed differences in social play partner changes during the first year. Hill et al. (2007) reported individual differences in maternal behaviors of seven captive bottlenose dolphin females, including the mothers of the calves in this study. They observed that the mothers of NO and JO ranked low on maternal behaviors that are considered controlling, such as discipline and proximity maintenance. As a result, these mothers may have allowed their calves more independence to participate in social play with peers than mothers ranking higher in controlling behavior. Moreover, these mothers may have also allowed other calves to initiate social play behaviors with their calves without intervening.

When it comes to the initiation of social play, our results suggest that age similarity may be an important factor in determining who initiates a social play bout. When the calves were very young, they initiated a low percentage of social play behaviors. It may be that young calves initiated play less frequently in order to avoid rough responses by older, "tougher" individuals (Fagen, 1981; MendozaGrenados \& Sommer, 1995). However, as the calves aged and developed their social play skills, they began to initiate social play interactions more regularly.

In addition to age, the initiation of social play may also be influenced by the social structure of the group. As young calves have not yet established their position within the group's social hierarchy, they may not be comfortable soliciting play. Through a variety of social interactions, including social play, calves gain experience interacting with different members of their social group and learn with whom they can successfully initiate play.

The analysis of play partner preferences revealed that although the calves engaged in social play with all of the other calves, each calf had one preferred play partner. Age similarity seems to play a role in these preferences. For example, NO and JO, who were born two weeks apart, were each other's most common play partner throughout the study. This suggests that the closer in age two calves are, the more likely they are to play with each other. A similar play partner preference has been reported in other social species, including bighorn sheep (Ovis Canadensis; Hass \& Jenni, 1991), sable antelope (Thompson, 1996b) vervet monkeys, (Govindarajulu et al., 1993), gorillas (Maestripieri \& Ross, 2004), and chimpanzees (Cordoni \& Palagi, 2011; Mendoza-Granados \& Sommer, 1995).

Young animals may show a preference for similarly-aged peers as play partners because of the perceptual similarity between them (Kuczaj et al., 2006). This similarity may facilitate the calf's mental representation of the behaviors performed by another calf, increasing the likelihood that the behavior will be reproduced (Yando, Seitz, \& Zigler, 1978). Likewise, 1-aged peers are often in a comparable stage of development and therefore well-matched in size, strength, and skills (Thompson, 1996b). As a result, play with like-aged peers provides immediate feedback on their manipulative, locomotor, and competitive social skills, allowing an individual to assess their own developmental competence (Thompson, 1996b, 1998).

Although young animals tend to play most frequently with partners of equivalent age/skill, they still engage in play with older, more advanced individuals. When play does occur between a young animal and an older play partner, it often involves self-handicapping in which the larger, more skilled individual adjusts its play to match that of the less skilled individual (Bekoff \& Allen, 1998; Biben, 1998; Fagen, 1981; Mendoza-Granados \& Sommer 1995; Spinka et al., 2001, Watson \& Croft, 1996). By participating in challenging activities, such as play with more advanced conspecifics, young animals are able to manage their development, staying with easier activities if the outcome was failure, or advancing to more difficult activities if the outcome was success (Thompson, 1998).

Our results support this self-assessment theory (Thompson, 1998). NO and JO were born within weeks of one another and were, therefore, in similar stages of development. As these calves aged they began to engage more frequently in social play with the older calves, JA and KA. Play with older calves would provide a more challenging and stimulating situation by introducing moderately discrepant events, in which the play behaviors would be both familiar and novel at the same time (Kuczaj et al., 2006; Piaget, 1952). Similarly, as NO and JO grew more competent in their social play skills it is likely that they became more attractive as play partners for JA and KA, and were solicited for social play interactions more frequently. 


\section{Conclusions}

The age and type of play partners in a social group of animals has important implications for developing animals. Play with the mother initially serves in strengthening the bond between a mother and infant, while play with peers may allow a young animal to develop its social skills more efficiently, adapt to novel situations, enhance motor skills, train for mature social interactions, and advance its cognitive abilities (Bekoff \& Byers, 1981; Burghardt, 2005; Coelho \& Bramblett, 1982; Fagen, 1981; Kuczaj et al., 2006, Kuczaj \& Makecha, 2008; Martin \& Caro, 1985). Additionally, the importance of peers as play partners may have significant implications for social groups housed in zoological facilities. Zoo-housed animals do not face the same environmental pressures as their free-ranging counterparts (e.g., predator avoidance, foraging), which provides them with more time to engage in alternative behaviors, such as play (Loizos, 1976; Thompson, 1996a). Play has been reported to be suppressed in sick or stressed animals, thus playfulness may be an indicator of an animal's health and welfare (Fagen, 1981; Held \& Spinka, 2011). Likewise, the frequency of play can also be used as a measure of the enriching quality of a captive environment (Kuczaj, Lacinak, \& Turner, 1998). Providing zoo animals with a broad range of play opportunities, including appropriate play partners, may help prevent both psychological and behavioral deficits (Fagen, 1981; Kuczaj et al., 1998; Thomspon, 1996a).

Although the current study revealed interesting developmental patterns of social play in bottlenose dolphin calves, there are limitations to our conclusions due to small sample size. For example, sex differences may have contributed to some of our results, such as the differences in the pattern of social play of KA versus NO/JO. Unfortunately, with only three subjects (and only one female), we were not able to examine sex differences in the development of social play. Future studies should be designed to utilize data from multiple institutions, thus increasing sample size and allowing for a more thorough analysis of social play development in bottlenose dolphins. We suggest that these studies incorporate focal animal sampling to examine whether 1) sex differences exist in the type and frequency of play in dolphin calves, 2) the dominance status of the mother has an effect on social play frequency in calves, and 3) a mother's vigilance during her calf's social play is influenced by the type of partner with which her calf is interacting (i.e., similarly-aged or older calf).

\section{Acknowledgements}

We wish to thank all the students, interns, and volunteers at the Marine Mammal Behavior and Cognition $\mathrm{Lab}$ at the University of Southern Mississippi for their assistance in data collection, as well Marine Life Oceanarium for providing the opportunity to observe their animals. We also thank R. Kristiansen, L. Miller, and several anonymous reviewers for their insights, which substantially improved this manuscript.

\section{References}

Altmann, J. (1974). Observational study of behavior: Sampling methods. Behaviour, 49, 227-267.

Altmann, S. A. (1962). Social behavior of anthropoid primates: Analysis of recent concepts. In E. L. Bliss (Ed.), Roots of behavior (pp. 277-285). New York: Harper.

Avital, E., \& Jablonka, E. (2000). Animal traditions: Behavioral inheritance in evolution. Cambridge, UK: Cambridge University Press.

Bekoff, M., \& Allen, C. (1998). Intentional communication and social play: How and why animals negotiate and agree to play. In M. Bekoff \& J. A. Byers (Eds.), Animal play: Evolutionary, comparative, and ecological perspectives (pp. 97-114). Cambridge, UK: Cambridge University Press.

Bekoff, M., \& Byers, J. (1981). A critical reanalysis of the ontogeny of mammalian social and locomotor play: An ethological hornet's nest. In W. Barlow, K. Immelman, \& L. Petrinovich (Eds.), Behavioural development: The Bielefeld Interdisciplinary Project (pp. 296-337). New York: Cambridge University Press.

Biben, M. (1998). Squirrel monkey play fighting: Making the case for a cognitive training function for play. In M. Bekoff \& J. A. Byers (Eds.), Animal play: Evolutionary, comparative, and ecological perspectives (pp. 161-182). Cambridge, UK: Cambridge University Press. 
Blomqvist, C., Mello, I., \& Amundin, M. (2005). An acoustic play-fight signal in bottlenose dolphins (Tursiops truncatus) in human care. Aquatic Mammals, 31, 187-194.

Boyd, R., \& Richerson, P. J. (1988). An evolutionary model of social learning: The effects of spatial and temporal variation. In T. Zentall \& B. G. Galef (Eds.), Social learning: Psychological and biological perspectives (pp. 29-48). Hillsdale, NJ: Erlbaum.

Brown, D. H., \& Norris, K. S. (1956). Observations of captive and wild cetaceans. Journal of Mammalogy, 37, 311326.

Burghardt, G. M. (1998). The evolutionary origins of play revisited: Lessons from turtles. In M. Bekoff \& J. A. Byers (Eds.), Animal play: Evolutionary, comparative, and ecological perspectives (pp. 1-26). Cambridge, UK: Cambridge University Press.

Burghardt, G. M. (2005). The genesis of animal play. Cambridge, MA: MIT Press.

Byers, J. A. (1977). Terrain preferences in the play behavior of Siberian ibex kids (Capra ibex sibirica). Zeitschrift Fur Tierpsychologie, 45, 199-209.

Cheney, D. L. (1978). The play partners of immature baboons. Animal Behaviour, 26, 1038-1050.

Chirighin, L. (1987). Mother-calf spatial relationships and calf development in the captive bottlenose dolphin (Tursiops truncatus). Aquatic Mammals, 13, 5-15.

Cockcroft, V. G., \& Ross, G. J. B. (1990). Observations on the early development of captive bottlenose dolphin calf. In S. Leatherwood \& R. R. Reeves (Eds.), The bottlenose dolphin (pp. 461-478). New York: Academic Press.

Coelho, A. M., Jr., \& Bramblett, C. A. (1982). Social play in differentially reared infant and juvenile baboons (Papio sp.). American Journal of Primatology, 3, 153-160.

Connor, R. C., Smolker, R., \& Bejder, L. (2006). Synchrony, social behaviour and alliance affiliation in Indian Ocean bottlenose dolphins, Tursiops aduncus. Animal Behaviour, 72, 1371-1378.

Connor, R. C., Smolker, R. A., \& Richards, A. F. (1992). Two levels of alliance formation among male bottlenose dolphins (Tursiops sp.). Proceedings of the National Academy of Sciences, 89, 987-990.

Cordoni, G., \& Palagi, E. (2011). Ontogenetic trajectories of chimpanzee social play: Similarities with humans. PLoS ONE, 6, e27344. doi: 10.1371/journal.pone.0027344

DeLong, T. C. (1999). Observations of free-play behavior in captive juvenile bottlenose dolphins (Tursiops truncatus). In R. S. Reifel (Ed.), Play contexts revisited (pp. 219-236). Stamford, CT: Ablex Publishing Corporation.

Diamond, J., \& Bond, A. B. (2003). A comparative analysis of social play in birds. Behaviour, 140, 1091-1115.

Doyle, A. B., Connolly, J., \& Rivest, L. P. (1980). The effect of playmate familiarity on the social interactions of young children. Child Development, 51, 217-223.

Drea, C. M., Hawk, J. E., \& Glickman S. E. (1996). Aggression decreases as play emerges in infant spotted hyaenas: Preparation for joining the clan. Animal Behaviour, 51, 1323-1336.

Dudzinski, K. M., Gregg, J., Melillo-Sweeting, K., Seay, B., Levengood, A., \& Kuczaj, S. A. II (2012). Tactile contact exchanges between dolphins: Self-rubbing versus inter-individual contact in three species from three geographies. International Journal of Comparative Psychology, 25, 21-43.

Dudzinski, K. M., Gregg, J. D., Ribic, C. A., \& Kuczaj, S. A. II (2009). A comparison of pectoral fin contact between two different wild dolphin populations. Behavioural Processes, 80, 182-190.

Eckerman, C. O., Whatley, J. L., \& Kutz, S. L. (1975). Growth of social play with peers during the second year of life. Developmental Psychology, 11, 42-49.

Eastcott, A., \& Dickinson, T. (1987). Underwater observations of the suckling and social behavior of a new-born bottlenosed dolphin (Tursiops truncatus). Aquatic Mammals, 13, 51-56.

Essapian, F. S. (1953). The birth and growth of a porpoise. Natural History, 62, 392-399.

Fady, J. C. (1969). Les jeux sociaux: Le compagnon de jeux chez les jeunes. Folia Primatologica, 11, 134-143.

Fagen, R. (1981). Animal play behaviour. New York: Oxford University Press.

Fry, D. P. (2005). Rough-and-tumble social play in humans. In A. D. Pellegrini \& P. K. Smith (Eds.), The nature of play: Great apes and humans (pp. 54-85). New York: Guilford Press.

Gentry, R. L. (1974). The development of social behavior through play in the Steller sea lion. American Zoologist, 14, 391-403.

Gibson, Q. A., \& Mann, J. (2008a). The size, composition and function of wild bottlenose dolphin (Tursiops sp.) mother-calf groups in Shark Bay, Australia. Animal Behaviour, 76, 389405.

Gibson, Q. A., \& Mann, J. (2008b). Early social development in wild bottlenose dolphins: Sex differences, individual variation and maternal influence. Animal Behaviour, 76, 375-387. 
Gomendio, M. (1988). The development of different types of play in gazelles: Implications for the nature and functions of play. Animal Behaviour, 36, 825-836.

Goodall, J. (1968). The behaviour of free living chimpanzees in the Gombe Stream Reserve. Animal Behavior Monographs, 1, 163-311.

Gottlieb, G. (2002). Developmental-behavioral initiation of evolutionary change. Psychological Review, 109, 211218.

Govindarajulu, P., Hunte, W., Vermeer, L. A., \& Horrocks, J. A. (1993). The ontogeny of social play in a feral troop of vervet monkeys (Cercopithecus aethiops sabaeus): The function of early play. International Journal of Primatology, 14, 701-719.

Greene, W. E., Melillo-Sweeting, K., \& Dudzinski, K. M. (2011). Comparing object play in captive and wild dolphins. International Journal of Comparative Psychology, 24, 292-306.

Gubbins, C., McCowan, B., Lynn, S. K., Hooper, S., \& Reiss, D. (1999). Mother-infant spatial relations in captive bottlenose dolphins, Tursiops truncatus. Marine Mammal Science, 15, 751-765.

Guinet, C. (1991). Intentional stranding apprenticeship and social play in killer whales (Orcinus orca). Canadian Journal of Zoology, 69, 2712-2716.

Harcourt, R. (1991). The development of play in the South American fur seal. Ethology, 88, 191- 202.

Harlow, H. F., \& Harlow, M. (1962). Social deprivation in monkeys. Scientific American, 207, 136-146.

Hass, C. C., \& Jenni, D. A. (1991). Structure and ontogeny of dominance relationships among bighorn rams. Canadian Journal of Zoology, 69, 471-476.

Held, S. D. E., \& Spinka, M. (2011). Animal play and animal welfare. Animal Behaviour, 81, 891-899.

Henry, J. D., \& Herrero, S. M. (1974). Social play in the American black bear: Its similarity to canid social play and an examination of its identifying characteristics. American Zoologist, 14, 371-389.

Hill, H. M., Greer, T., Solangi, M., \& Kuczaj, S. A., II (2007). All mothers are not the same: Maternal styles in bottlenose dolphins (Tursiops truncatus). International Journal of Comparative Psychology, 20, 35-54.

Hoff, M. P., Nadler, R. D., \& Maple, T. L. (1981). The development of infant play in a captive group of lowland gorillas (Gorilla gorilla gorilla). American Journal of Primatology, 1, 65-72.

Holmes, W. G. (1994). The development of littermate preferences in juvenile Belding's ground squirrels. Animal Behaviour, 48, 1071-1108.

Imakawa, S. (1990). Playmate relationships of immature free-ranging Japanese monkeys at Katsuyama. Primates, $31,509-521$.

Itani, J. (1954). Takasakiyama no Saru. Tokyo: Kounsha.

Kuczaj, S. A., II, Lacinak, C. T., \& Turner, T. N. (1998). Environmental enrichment for marine mammals at Sea World. In D. Shepherdson, J. Mellen, \& M. Hutchins (Eds.), Second nature: Environmental enrichment for captive animals (pp. 314-328). Washington, DC: Smithsonian Institution.

Kuczaj, S. A., \& Makecha, R. (2008). The role of play in the evolution and ontogeny of contextually flexible communication. In D. K. Oller \& U. Griebel (Eds.), Evolution of communicative flexibility: Complexity, creativity, and adaptability in human and animal communication (pp. 253-277). Cambridge, MA: MIT Press.

Kuczaj, S. A., II, Makecha, R. N., Trone, M., Paulos, R. D., \& Ramos, J. A. (2006). Role of peers in cultural innovation and cultural transmission: Evidence from the play of dolphin calves. International Journal of Comparative Psychology, 19, 223-240.

Kuczaj, S. A., II, Paulos, R. D., Ramos, J. A. (2005). Imitation in apes, children and dolphins: Implications for the ontogeny and phylogeny of symbolic representation. In L. L. Namy (Ed.) Symbol use and symbolic representation: Developmental and comparative perspectives (pp. 221-243). Mahwah, NJ: Erlbaum.

Kuczaj, S. A., II, \& Trone, M. (2001). Why do dolphins make their play more difficult? Genetic Epistemologist, 29, 57.

Laland, K. N., Odling-Smee, J., \& Feldman, M. W. (2000). Niche construction, biological evolution, and cultural change. Behavioral and Brain Sciences, 23, 131-175.

Lee. P. C. (1987). Allomothering in African elephants. Animal Behaviour, 35, 278 - 291.

Loizos, C. (1967. Play behaviour in higher primates: A review. In D. Morris \& D. Bruce (Eds.), Primate ethology (pp. 176-218). London: Wiedenfeld \& Nicholson.

Lusseau, D., Schneider, K., Boisseau, O. J., Haase, P., Slooten, E., \& Dawson, S. M. (2003). The bottlenose dolphin community of Doubtful Sound features a large proportion of long-lasting associations. Behavioral Ecology and Sociobiology, 54, 396-405. 
Maestripieri, D., \& Ross, S. R. (2004). Sex differences in play among western lowland gorilla (Gorilla gorilla gorilla) infants: Implications for adult behavior and social structure. American Journal of Physical Anthropology, 12, 52-61.

Mann, J. (1997). Individual differences in bottlenose dolphin infants. Family Systems, 4, 35-49.

Mann, J. (2006). Establishing trust: Socio-sexual behaviour among Indian Ocean bottlenose dolphins and the development of male-male bonds. In V. Sommer \& P. L. Vasey (Eds.), Homosexual behaviour in animals: An evolutionary perspective (pp. 107-130). New York: Cambridge University Press.

Mann, J., \& Smuts, B. (1999). Behavioral development in wild bottlenose dolphin newborns (Tursiops sp). Behaviour, 136, 529-566.

Martin, P., \& Caro, T. M. (1985). On the functions of play and its role in behavioural development. Advances in the study of behavior, 15, 59-103.

McBride, A. F., \& Hebb, D. O. (1948). Behavior of the captive bottle-nose dolphin, Tursiops truncatus. Journal of Comparative Physiology and Psychology, 41, 111-123.

McBride, A. F., \& Kritzler, H. (1951). Observations on the pregnancy, parturition, and post natal behavior in the bottlenose dolphin. Journal of Mammalogy 32, 251-266.

Mello, I., Nordensten, L., \& Amundin, M. (2005). Reactions of three bottlenose dolphin dams with calves to other members of the group in connection with nursing. Zoo Biology, 24, 543-555.

Mendl, M. (1988). The effects of litter-size variation on the development of play behaviour in the domestic cat: Litters of one and two. Animal Behaviour, 36, 20-34.

Mendoza-Granados, D., \& Sommer, V. (1995). Play in chimpanzees of the Arnhem zoo: Self-serving compromises. Primates, 36, 57-68.

de Oliveira, C. R., Ruiz-Miranda, C. R., Kleiman, D. G., \& Beck, B. B. (2003). Play behavior in juvenile golden lion tamarins (Callitrichidae: Primates): Organization in relation to costs. Ethology, 109, 593-612.

Owens, N. W. (1975). Social play behaviour in free living baboons, Papio anubis. Animal Behaviour, 23, 387-408.

Pace, D. S. (2000). Fluke-made bubble rings as toys in bottlenose dolphin calves (Tursiops truncatus). Aquatic Mammals, 26, 57-64.

Palagi, E., Cordoni, G., \& Borgognini Tarli, S. M. (2004). Immediate and delayed benefits of play behaviour: New evidence from chimpanzees (Pan troglodytes). Ethology, 110, 949-962.

Paulos, R. D., Trone, M., \& Kuczaj, S. A., II (2010). Play in wild and captive cetaceans. International Journal of Comparative Psychology, 23, 701-722.

Piaget, J. (1952). The origins of intelligence in children. New York: International Universities Press.

Poirier, F. E., \& Smith, E. O. (1974). Socializing functions of primate play. American Zoologist, 14, 275-287.

Pozis-Francois, O., Zahavi, A., \& Zahavi, A. (2004). Social play in Arabian babblers. Behaviour, 141, 425-450.

Reid, K., Mann, J., Weiner, J. R., \& Hecker, N. (1995). Infant development in two aquarium bottlenose dolphins. Zoo Biology, 14, 135-147.

Rendell, L., \& Whitehead, H. (2001). Culture in whales and dolphins. Behavioral and Brain Sciences, 24, 309-382.

Renouf, D., \& Lawson, J. W. (1986). Play in harbour seals (Phoca vitulina). Journal of Zoology, 208, 73-82.

Rogers, C. A., Brunnick, B. J., Herzing, D. L., \& Baldwin, J. D. (2004). The social structure of bottlenose dolphins, Tursiops truncatus, in the Bahamas. Marine Mammal Science, 20, 688-708.

Rothstein, A., \& Griswold, J. G. (1991). Age and sex preferences for social partners by juvenile bison bulls, Bison bison. Animal Behaviour, 41, 227-237.

Scholtz, G. J. L., \& Ellis, M. J. (1975). Repeated exposure to objects and peers in a play setting. Journal of Experimental Child Psychology, 19, 448-455.

Spinelli, L. H. P., Nascimento, L. F., \& Yamamoto, M. E. (2002). Identification and description of play in a scarcely studied species, the tucuxi (Sotalia fluviatilis) in a field site. Estudos de Psicologia, 7, 165-171.

Spinka, M., Newberry, R. C., \& Bekoff, M. (2001). Mammalian play: Training for the unexpected. Quarterly Review of Biology, 76, 141-168.

Sylvestre, J. P. (1985). Some observations on behaviour of two Orinoco dolphins (Inia geoffrensis humboldtiana) (Pilleri \& Gihr, 1977), in captivity at Duisburg Zoo. Aquatic Mammals, 11, 58-65.

Tamaki, N., Morisaka, T, \& Taki, M. (2006). Does body contact contribute towards repairing relationships?: The association between flipper-rubbing and aggressive behavior in captive bottlenose dolphins. Behavioural Processes, 73, 209-215.

Tartabini, A. (1991). Social play behaviour in young rhesus monkeys Macaca mulatta at three different ages: From the $3^{\text {rd }}$ to the $6^{\text {th }}$ month of life. Behavioural Processes, 24, 185-192.

Tavolga, M. C., \& Essapian, F. S. (1957). The behavior of the bottlenose dolphin, Tursiops truncatus: Mating, pregnancy and parturition, mother-infant behavior. Zoologica, 42, 11-31. 
Tayler, C. K., \& Saayman, G. S. (1972). The social organization and behavior of dolphins (Tursiops aduncus) and baboons (Papio ursinus): Some comparisons and assessments. Annals of Cape Provincial Museums (Natural History), 9, 11-49.

Thompson, K. V. (1996a). Behavioral development and play. In D. G. Kleiman, M. E. Allen, K. V. Thompson, \& S. Lumpkin (Eds.), Wild mammals in captivity: Principles and techniques (pp. 352-371). Chicago: University of Chicago Press.

Thompson, K. V. (1996b). Play-partner preferences and the function of social play in infant sable antelope, Hippotragus niger. Animal Behaviour, 52, 1143-1155.

Thompson, K. V. (1998). Self assessment in juvenile play. In M. Bekoff \& J. A. Byers (Eds.), Animal play: Evolutionary, comparative, and ecological perspectives (pp. 183-204). Cambridge, UK: Cambridge University Press.

Watson, D. M., \& Croft, D. B. (1996). Age-related differences in play-fighting strategies of captive male red-necked wallabies (Macropus rufogriseus banksianus). Ethology, 102,336-346.

Wells, R. S., Scott, M. D., \& Irvine, A. B. (1987). The social structure of free-ranging bottlenose dolphins. Current Mammalogy, 1, 247-305.

Wemmer, C., \& Fleming, M. J. (1974). Ontogeny of playful contact in a social mongoose, the meerkat, Suricatta suricatta. American Zoologist, 14, 415-426.

Yando, R., Seitz, V., \& Zigler, E. (1978). Imitation: A developmental perspective. Hillsdale, NJ: Erlbaum. 


\section{Appendix}

Ethogram of Target Play Behaviors

\begin{tabular}{|c|c|}
\hline Play behavior & Description \\
\hline Social play & Play behavior involving two or more dolphins. \\
\hline Chase & $\begin{array}{l}\text { One dolphin quickly and actively pursues another; } \\
\text { individuals may take turns as chaser. }\end{array}$ \\
\hline Bite/mouth & $\begin{array}{l}\text { One dolphin rubs/slides jaw along the body of another or } \\
\text { quickly opens and closes mouth with force near another } \\
\text { dolphin's body. }\end{array}$ \\
\hline Rough-and-tumble play & $\begin{array}{l}\text { Two or more dolphins roll over and around each other in } \\
\text { the water column as though wrestling; involves surface } \\
\text { splashing and may involve biting or mouthing. }\end{array}$ \\
\hline Object play & $\begin{array}{l}\text { Two dolphins interact with the same object such as a ball, } \\
\text { buoy, feather, etc.; may involve sharing an object (e.g., } \\
\text { passing an object back and forth), or stealing an object } \\
\text { from another dolphin. }\end{array}$ \\
\hline Bubble play & $\begin{array}{l}\text { One dolphin bites or manipulates bubble(s) or bubble- } \\
\text { ring(s) produced by another dolphin; individuals may take } \\
\text { turns producing/biting bubbles. }\end{array}$ \\
\hline Solitary play & Play behavior produced by a single dolphin. \\
\hline Object play & $\begin{array}{l}\text { Dolphin plays with an object such as a ball, buoy, feather, } \\
\text { etc.; may involve pushing, tossing, bouncing, carrying, or } \\
\text { trapping object (e.g., against bottom of pool). }\end{array}$ \\
\hline Bubble play & $\begin{array}{l}\text { Dolphin bites or manipulates bubble(s) or bubble-ring(s) it } \\
\text { produces itself. }\end{array}$ \\
\hline Water play & Dolphin tosses and/or catches water. \\
\hline
\end{tabular}

